Kalina Grzesiuk

John Paul II Catholic University of Lublin

Faculty of Social Sciences

e-mail: grzesiuk@kul.pl

\title{
Unethical Behaviour of Organisations from a Social Network Perspective. A Literature Review
}

\begin{abstract}
One of the distinctive features of contemporary organisations is their interconnectedness. Relationships between companies are usually analysed on the basis of social network relationships between them. The research question this article aims to answer concerns the influence of being part of an interorganisational network on the occurrence and consequences of unethical behaviour.

This paper covers three main areas of research regarding this topic. Firstly, the role networks play in the initiation, evolution, and consequences of wrongdoings. The main problem taken into consideration in this part of the article is identifying network factors which increase and mitigate the propensity of organisations to deceive their partners. Two main types of such determinants include relational and structural factors. The first group usually involves features such as the strength of ties, the symmetry/asymmetry of ties, and the status of partners. The latter includes such variables as structural holes, centrality, density and the cohesiveness of the network. The second area covered in this article concerns how misconduct behaviours spread throughout the network of interorganisational ties. This phenomenon might resemble a social or emotional contagion occurring in social networks. The effects of unethical acts on the network are the main interest of the third part of this paper. Usually, the consequences of wrongdoing by one of the interconnected partners include a change in the quality of the related partners, modifications in the structure of the network, and an alteration of its prominence and cohesion. In conclusion, there are some suggestions for lines of inquiry in the area of unethical behaviour from the social network perspective in the future.
\end{abstract}

Keywords: unethical behaviours, network, interorganisational relationships, social networks

JEL Classification: M10, M14, Z13 


\section{Introduction}

Contemporary organisations function in a very complex and uncertain environment. Globalization, technical progress, and steadily increasing market competition require creating new forms of cooperation based on interconnectedness. Networks of organisations operate in a different way from that of a single organisation and that specificity influences also the ethical sphere of their behaviours. ${ }^{1}$ The aim of this paper is to outline a theoretical framework and suggest some implications for future research concerning the initiation, spread and consequences of unethical behaviours from a social network perspective. Review and critical examination of the related literature allow to explore possible linkages between interconnectedness and ethics in an organisational setting.

Even a cursory survey of the literature shows that there are numerous terms used to describe the act of unethical behaviour. Greve, Palmer and Pozner write about misconduct, defining it as 'behaviour in or by an organisation that a socialcontrol agent judges to transgress a line separating right from wrong, where such a line can separate legal, ethical and socially responsible behaviour from their antithesis. ${ }^{2}$ This is a very broad definition but it introduces a very important observation concerning the nature of an unethical act. The evaluation of behaviour is subjective and based upon comparison to the system of norms specific for some community like world polity, the state, or professional associations. That is why these authors stress the importance of social control agents as institutions representing a collectivity that can impose sanctions on that collectivity's behalf.

Social control agents' actions are also supported by media. Although these cannot impose legal punitive sanctions, they have the ability to frame behaviour and put pressure on social control agents to directly penalize unethical acts. The influence of media consists mostly in scrutiny, spreading information about the unethical behaviour, and applying more indirect means of punishment, such as humiliation. ${ }^{3}$

Sullivan, Haunschild and Page use the broad term unethical behaviours and define it as 'acts that are illegal under state or federal laws or acts that are unacceptable for the larger community. ${ }^{4}$ Johnson, Grieve and Fujiwara-Grieve write about corporate deviance stressing the sphere of societal norms and the process of losing social legitimization of organisation' activities. ${ }^{5}$ These definitions stress the importance not

\footnotetext{
${ }^{1}$ Some of these unique features of networks of organisations in: K.G. Provan, A. Fish, J. Sydow, Interorganizational Networks at the Network Level: A Review of the Empirical Literature on Whole Networks, "Journal of Management" 2007, Vol. 33, No. 3, p. 481.

${ }^{2}$ H.R. Greve, D. Palmer, J. Pozner, Organizations Gone Wild: The Causes, Processes, and Consequences of Organizational Misconduct, "The Academy of Management Annals" 2010, Vol. 4, No. 1, p. 56.

${ }^{3}$ Ibidem, p. 57.

${ }^{4}$ B.N. Sullivan, P. Haunschild, K. Page, Organizations Non Gratae? The Impact of Unethical Corporate Acts on Interorganizational Networks, "Organization Science” 2007, Vol. 18, No. 1, p. 56.

${ }^{5}$ S. Jonsson, H.R. Greve, T. Fujiwara-Greve, Undeserved Loss: The Spread of Legitimacy Loss to Innocent Organizations in Response to Reported Corporate Deviance, "Administrative Science Quarterly" 2009, Vol. 54, No. 2, p. 195.
} 
only of legal aspects but also social norms of a given community. Thus, if we consider cultural differences between various collectivities, it might be a confirmation of subjectivity of the perception of whether an organisation breaks the rules or not.

Research on wrongdoing can include only behaviours that violate a society's laws or, broadly, any behaviour considered deviant from the social norms and ethical principles. ${ }^{6}$ In this article it is conceptualized broadly and including all behaviours ranging from unethical to illegal.

\section{Levels of research on unethical behaviours}

Research on organisational unethical behaviour is usually discussed on individual, organisational $^{7}$ or interorganisational level where it concerns networks of organisations. Individual factors often include personal norms, cost-benefit analysis, unconscious motivations, intuition, emotion or, recently, moral seduction theory ${ }^{8}$ while the organisational ones concern individuals interrelated within the structure of a company. ${ }^{9}$ And among these factors often listed as factors of misconduct are strain, culture and networks. ${ }^{10}$ The first two could also be a subject of research on the interorganisational level.

Strain might be a source of unethical behaviour when individuals are unable to achieve goals set for them using legitimate means. When organisations are under strain individuals tend to be more prone to unethical behaviour. This is more visible in for profit than in non-profit organisations. The main source of the problem is the level of managerial aspirations in the organisation. That is why strain can be present even when the actual situation of a company does not indicate the need for it. ${ }^{11}$ Strain is also prevalent in organisations placing a high value on

\footnotetext{
${ }^{6}$ D. Palmer, C. Moore, Social Networks and Organizational Wrongdoing in Context [in:] Organizational Wrongdoing, eds. D. Palmer, R. Greenwood, K. Smoth-Crowe, Cambridge University Press, Cambridge 2016, pp. 153-170.

${ }^{7}$ Research concerning unethical behaviours of organisations is based on an anthropomorphic view of organisations in terms of which audiences perceive 'actions by agents of the organisation as actions by the organisation itself' (J.A.M. Coyle-Shapiro, L.M. Shore, The employee-organization relationship: Where do we go from here?, "Human Resource Management Review" 2007, Vol. 17, No. 2, pp. 169). Although this assumption may be seen as controversial, it has been frequently relied on in the related social science literature since 1960 s.

${ }^{8}$ Literature review on this topic in: A.E. Tenbrunsel, K. Smith-Crowe, Ethical Decision Making: Where We've Been and Where We're Going, "The Academy of Management Annals" 2008, Vol. 2, No. 1, pp. 545-607, or B.E. Ashforth, D.A. Gioia, S.L. Robinson, L.K. Treviño, Re-Viewing Organizational Corruption, “Academy of Management Review” 2008, Vol. 33, No. 3, pp. 670-684.

${ }^{9}$ Broader characteristics and comparison of these two approaches in: J. Pinto, C.R. Leana, F.K. Pil, Corrupt or Organizations of Corrupt Individuals? Two Types of Organization-Level Corruption, “Academy of Management Review” 2008, Vol. 33, No. 3, pp. 685-709.

${ }^{10}$ H.R. Greve, D. Palmer, J. Pozner, op. cit., pp. 64-68.

${ }^{11}$ Research on the influence of differences between performance and aspiration on the likelihood of financial misrepresentation in: J. Harris, P. Bromiley, Incentives to Cheat: The Influence of Executive Compensation and Firm Performance on Financial Misrepresentation, "Organization Science" 2007, Vol. 18, No. 3, pp. 350-367.
} 
achieving extremely high performance. That usually leads to substantial pressure on employees by their superiors. Although the research concerning strain on a level broader than a single organisation is scarce, it might also be an interesting subject of research. The pressure imposed by cooperators, fierce competition or regulations of the state difficult to fulfil might provoke organisations to make decisions to act outside accepted legal, social or ethical norms.

Cultural norms and values present in an organisation might also provide support for unethical behaviours. Culture might facilitate such attitudes by more or less explicit endorsement of misconduct in organisational behaviours. ${ }^{12}$ Cultural norms may stress the importance of achieving goals but without guidance on how to achieve them. In more explicit ways, organisational culture might be based upon the importance of formulating and achieving goals, but without concern about the moral character of means. ${ }^{13}$ The endorsement of misconduct is clearly visible when organisational culture is based upon norms accepting and appreciating actions that are against rules, if they lead to positive outcomes for organisation.

Another area of cultural support for unethical behaviours can be seen when an organisation implements actions leading to making guilt less serious. There are specific techniques of so-called neutralization that are used to justify deviant behaviour. ${ }^{14}$ These include: ${ }^{15}$

(1) Denial of responsibility - for example perceiving the unethical behaviour as unintentional, a result of some kind of accident or some other negation of personal or organisational responsibility.

(2) Denial of injury - making the wrongfulness of the act subjective, perceiving it rather as not causing any real harm, so that the link between the crime and its consequences is absent.

(3) Denial of the victim - even if an organisation accepts the responsibility for the act and acknowledges the hurt, the guilt can be neutralized by stressing the importance of circumstances. Usually, that involves argumentation based upon a previous fault of the partner, so the unethical act is a form of repayment or revenge and generally speaking the 'victim' deserved it. That behaviour is especially facilitated if the partner is abstract, not someone that the organisation is directly linked with.

\footnotetext{
${ }^{12}$ N.M. Ashkanasy, C.A. Windsor, L.K. Treviño, Bad Apples in Bad Barrels Revisited: Cognitive Moral Development, Just World Beliefs, Rewards, and Ethical Decision-Making, "Business Ethics Quarterly" 2006, Vol. 16, No. 4, pp. 449-473.

${ }^{13}$ B.W. Kulik, Agency Theory, Reasoning and Culture at Enron: In Search of a Solution, "Journal of Business Ethics" 2005, Vol. 59, No. 4, pp. 347-360.

${ }^{14}$ G.M. Sykes, D. Matza, Techniques of Neutralization: A Theory of Delinquency, "American Sociological Review" 1957, Vol. 22, No. 6, pp. 667-669. The analysis in the organisational setting in: B.E. Ashforth, V. Anand, The Normalization of Corruption in Organizations, "Research in Organizational Behavior" 2003, Vol. 25, No. 2, pp. 1-52.

${ }^{15}$ G.M. Sykes, D. Matza, op. cit., pp. 667-669. For organisational setting compare: B.E. Ashforth, V. Anand, op. cit.
} 
(4) The condemnation of the condemners - an organisation may try to divert the attention from itself stressing the need to understand the motivation of partners questioning the ethics of its behaviour.

(5) The appeal to higher loyalties - arguments used in this technique stress that the organisation accused of misconduct was trying to solve the conflict between particularistic and universalistic demands and chose to satisfy norms favouring some smaller group of shareholders.

The cultural influence might also be considered at the macro level, as a culture of a country or nation may include norms supporting some unethical behaviours. Thus, intercultural differences might be a source of varying attitudes towards unethical behaviours among interconnected organisations.

\section{Networks' influence on unethical behaviour}

Applying network perspective to understanding the behaviour of organisations allows one to take into account mechanisms that are otherwise absent in organisational analysis. Most of organisational aspects, like actions and behaviour, can be more convincingly explained if we take into account existing ties between organisations.

One of the important mechanisms concerns the way network facilitates the alignment of norms and values. Social network ties can cause the imitation effect leading to adaptive responses within interorganisational networks that may reflect evidence of a social learning process. ${ }^{16}$ Haunschild and Miner introduce three types of imitation effect: frequency, trait and outcome. ${ }^{17}$ They concern, respectively, adoption of very common practices, practices of similar organisations, and practices with evident impact on others. The imitation effect provides an explanation why a connection to a broader network ensures the adoption of less controversial and more accepted universally practices. ${ }^{18}$ As some researchers show, it is the localized clusters with weaker links to the general network that are more prone to adapting controversial (unethical) practices. ${ }^{19}$

Another important influence of networks is the secrecy account. ${ }^{20}$ When organisations decide to take unethical action it is crucial for them to make sure that their misbehaviour remains secret. Thus, changes in the structure of a network might appear as an intended consequence of the need for secrecy and an attempt to exclude others from observing organisation's actions. The organisation is setting up structural conditions for ensuring that their unethical action remains undetected.

\footnotetext{
${ }^{16}$ E.M. Rogers, Diffusion of Innovations, The Free Press, New York, 1995.

${ }^{17}$ P.R. Haunschild, A.S. Miner, Modes of Interorganizational Imitation: The Effects of Outcome Salience and Uncertainty, "Administrative Science Quarterly” 1997, Vol. 42, No. 3, pp. 472-500.

${ }^{18}$ F. Briscoe, S. Safford, The Nixon-In-China Effect: Activism, Imitation, and the Institutionalization of Contentious Practices, “Administrative Science Quarterly” 2008, Vol. 53, pp. 460-491.

${ }^{19}$ G.F. Davis, H.R. Greve, Corporate Elite Networks and Governance Changes in the 1980s, "American Journal of Sociology" 1997, Vol. 103, No. 1, pp. 1-37.

${ }^{20}$ H.R. Greve, D. Palmer, J. Pozner, op. cit., p. 69.
} 
Research shows that some characteristics of the organisation and its network may also affect the range of sanctions. As Domènec Melé states, the main influence on the network in respect to the occurrence of unethical behaviour consists in providing the instruments of surveillance and effective transmission of reputation. ${ }^{21}$ However, some actors in a network can be protected from punitive reactions, because of the position they held in it, owing to their social capital and high status. ${ }^{22}$ Close ties with other individuals and organisations make it possible to draw on them in order to avoid or weaken the effects of stigmatization, once the information about the unethical behaviour spills out. ${ }^{23}$ Network contacts can help in disseminating the information and contradict stereotypes and attributes in the process of reputational sanctioning.

\section{Relational and structural factors}

Traditionally, the occurrence of unethical behaviour was perceived as dependent on various factors that could be divided into two main groups. The first group, sometimes called the 'bad apples' perspective, concentrated on the level of individuals in organisations and in this area researchers tried to identify their attributes forming the moral character of actors. The second group perceived this problem from 'bad barrels' perspective. The key areas of interest here were the attributes of organisations and society that facilitate misconduct.

However, Brass, Butterfield and Scaggs expanded this perception and constructed a model that consists of five main groups of factors. ${ }^{24}$ The first group consists of factors concerning individuals in organisation ('bad apples' perspective) and in this area the authors list factors including locus of control, cognitive moral development, and Machiavellism. The second group is consistent with the 'bad barrels' perspective and concentrates on organisational factors such as organisational climate, reward systems, norms and codes of conduct. The third group pertains to factors related to the issue of the act itself. In this case actors usually take into account magnitude of consequences, social consensus, probability of effect and proximity.

The two remaining groups concentrate on factors related to an organisation's network of ties, and take into account its relational and structural characteristics. Types of relationships concern features such as the strength of ties, status, multiplexity and asymmetry. The structure of relationships concentrates on the density of network, occurrence of cliques and structural holes, the centrality of a network.

\footnotetext{
${ }^{21}$ D. Melé, The Practice of Networking: An Ethical Approach, "Journal of Business Ethics" 2009, Vol. 90, No. 4, pp. 487-503.

${ }^{22}$ Examples in: P.S. Adler, S. Kwon, Social Capital: Prospects for a New Concept, "The Academy of Management Review" 2002, Vol. 27, No. 1, p. 31, http://doi.org/10.5465/AMR.2002.5922314, and J. Westphal, P. Khanna, Keeping Directors in Line: Social Distancing as a Control Mechanism in the Corporate Elite, “Administrative Science Quarterly" 2003, Vol. 48, No. 3, p. 392.

${ }^{23}$ B.M. Wiesenfeld, K.A. Wurthmann, D.C. Hambrick, The Stigmatization and Devaluation of Elites Associated with Corporate Failures: A Process Model, "Academy of Management Review”2008, Vol. 33, No. 1, p. 240.

${ }^{24}$ D.J. Brass, K.D. Butterfield, B.C. Skaggs, Relationships and Unethical Behaviour - A Social Network Perspective, "Academy of Management Review" 1998, Vol. 23, No. 1, pp. 14-31.
} 


\subsection{Relational factors}

Various scopes of network cohesiveness might lead to differing results. Closely tied networks usually lead to conformity, but in large networks they might also cause the emergence of local cliques that are very closely tied but also isolated from external networks. That makes them more prone to developing distinct norms and behaviours that might not be consistent with values generally perceived as ethical. ${ }^{25}$

The strength of ties can be measured in different ways, but many researchers accept Mark Granovetter's definition of it, as a function of an amount of time spent together, the emotional intensity, intimacy and reciprocal services. ${ }^{26}$ During repeated transactions between the same partners, economic relations become supported by social content that creates feelings of psychological proximity. Strong ties usually develop over time and history of previous transactions between partners. As a result, as they begin to trust each other, the need for ensuring safety with legal means of both parties decreases. Yet, as Granovetter acknowledges, trust also makes organisations more vulnerable and may enhance the opportunity of frauds. ${ }^{27}$

A multiplex relationship is a situation in which partners are interconnected by more than one type of relation. ${ }^{28}$ For example, economic exchange ties might be accompanied by social or family relations. This phenomenon exerts an important influence on the probability of unethical behaviour, because it increases the costs of misconduct, as it leads to breaking more than one type of relation.

Asymmetric relations appear when one partner has more power than the other. This situation might be dangerous for the weaker actor, especially where trust is not truly reciprocated. ${ }^{29}$ Yet, as Gulati and Sytch observe, even asymmetry of ties between partners doesn't necessarily lead to coercion. ${ }^{30}$ Their research found out that stronger partners were reluctant to abuse their relation, because of the recurrence of transactions with the same organisation. Their research proved that cooperative atmosphere may overweight the potential benefits achieved through coercion.

Another important factor influencing the likelihood of unethical act is status, in the sense of the relative power of one actor over another. ${ }^{31}$ Partners with a lower status usually are less willing to break the rules because of the risk of retaliation against them. Whilst among partners with a higher status the likelihood of such behaviour is highly dependent on organisational factors and norms.

${ }^{25}$ H.R. Greve, D. Palmer, J. Pozner, op. cit., p. 69.

${ }^{26}$ M. Granovetter, The Strength of Weak Ties, “American Journal of Sociology” 1973, Vol. 78, No. 6, pp. 1360-1380.

${ }^{27}$ Idem, Economic Action and Social Structure: The Problem of Embeddedness, "American Journal of Sociology" 1985, Vol. 91, No. 3, pp. 491-492.

${ }^{28}$ B. Uzzi, Social Structure and Competition in Interfirm Networks: The Paradox of Embeddedness,

“Administrative Science Quarterly” 1997, Vol. 42, No. 1, p. 48, http://doi.org/10.2307/2393808.

${ }^{29}$ D.J. Brass, K.D. Butterfield, B C. Skaggs, op. cit., pp. 18-19

${ }^{30}$ R. Gulati, M. Sytch, Dependence Asymmetry and Joint Dependence in Interorganizational Relationships: Effects of Embeddedness on a Manufacturer's Performance in Procurement Relationships, “Administrative Science Quarterly" 2007, Vol. 52, No. 1, pp. 32-69.

${ }^{31}$ D.J. Brass, K.D. Butterfield, B.C. Skaggs, op. cit., p. 19. 


\subsection{Structural factors}

Structural holes are 'separations between nonredundant contacts. ${ }^{32}$ Actors that hold positions in the network allowing them to act as bridges between networks not connected in any other way (over structural holes) 'are considered to be brokers, often occupying positions of considerable influence. ${ }^{33}$ An organisation that is the only link between two, otherwise non-connected parts of a network, has substantial power over partners in these sub-networks. They are dependent on that organisation for getting access to unique information and resources. That is why the risk of unethical behaviour on their part might be higher, than when they have a number of alternative interlinks.

Centrality is often defined as 'the extent to which an individual can reach others in the fewest number of direct and indirect links. ${ }^{34}$ There are two important aspects of the influence of centrality of actors' position on the likelihood of them taking unethical actions. Firstly, it might be riskier to do that if an organisation has a substantial number of direct connections, as it increases the level of surveillance. Having direct contacts with many partners means that there are more agents watching organisation's activities, so the risk of being caught is higher. Furthermore, the network of organisation's ties consisting of many indirect ties determines the number of others that might learn about the misconduct and that increases reputational costs of revealing the unethical behaviour.

The density of ties is another structural factor that influences the risk of unethical behaviours among interconnected organisations. This concept refers to the degree to which all individuals of a network are interconnected. ${ }^{35} \mathrm{~A}$ significant level of weak mutual ties might lead to similar reputational consequences as mentioned before. The risk of the diffusion of information about unethical behaviours can be a very effective means of discouragement for organisations, because losing reputation means tangible economic and market losses and probably will outgrow any potential benefits of misconduct. And in a closely-knit network based on trust reputation is critical.

As the number of actors in the network gets significantly larger, communication becomes difficult and, at times, the network brakes into cliques. ${ }^{36}$ These can be defined as distinct regions 'in a network of firms in which the interconnections among firms are denser than they are in other regions of network. ${ }^{37}$ In other words, these are groups of strongly tied homogeneous organisations. This internal

\footnotetext{
${ }^{32}$ R.S. Burt, Structural Holes, Harvard University Press, Harvard 1995, p. 18.

${ }^{33}$ K.G. Provan, A. Fish, J. Sydow, Interorganizational Networks at the Network Level: A Review of the Empirical Literature on Whole Networks, "Journal of Management" 2007, Vol. 33, No. 3, p. 484.

${ }^{34}$ D.J. Brass, K.D. Butterfield, B.C. Skaggs, op. cit., p. 21.

${ }^{35}$ M.T. Seevers, S.J. Skinner, S.W. Kelley, A Social Network Perspective on Sales Force Ethics, "Journal of Personal Selling \& Sales Force Management" 2008, Vol. 33, No. 1, pp. 231-251.

${ }^{36}$ Example of applying cliques in the network analysis to study mental health services in: K.G. Provan, J.G. Sebastian, Networks Within Networks: Service Link Overlap, Organizational Cliques, and Network Effectiveness, “Academy of Management Journal” 1998, Vol. 41, No. 4, pp. 453-463.

${ }^{37}$ T.J. Rowley, H.R. Greve, H. Rao, J.A. Baum, A.V. Shipilov, Time to Break Up: Social and Instrumental Antecedents of Firm Exits from Exchange Cliques, "The Academy of Management Journal", 2005, Vol. 48, No. 3, p. 499.
} 
homogeneity might lead to forming specific norms contrary to the ones accepted universally. The occurrence of such a phenomenon becomes more probable with the increase of the size of the network and it becomes more difficult to maintain ethical norms across fragmented cliques.

Conspiracy is a specific case of a group of organisations involved in unethical activities. It usually forms when the misconduct requires cooperation in order to be beneficial for the involved parties. Such grouping requires specific network characteristics. In order to avoid the spread of information about an illegitimate act, the outside network should consist of sparse, weakly tied actors. However, it is essential for the conspiracy to be successful that all the parties involved are connected in a network that is centralized, dense and strongly tied. These characteristics enable coordination of their actions and indispensable internal trust.

\section{Diffusion of misconduct through the network}

On the organisation level, the process of spreading of unethical behaviour might evolve in time and pass four main phases. The first stage of misconduct, called initiation, is usually concentrated on the individual level and may involve misbehaviour by a manager. In the second phase, the unethical behaviour travels down the organisational hierarchy. This proliferation stage usually concerns areas, such as culture, interaction, social learning and techniques of neutralization. ${ }^{38}$ The third phase involves institutionalization of misconduct. That means that acting in an unethical way gets embedded in the organisation, as it is supported by specific routines and structures. That allows them to be perceived as acceptable. The final stage is socialization. The support for unethical behaviour is so deeply engrained in the organisation, that it is imposed on new participants.

The spread of misconduct among organisations may arise as a result of the imitation effect, as an increasing number of interconnected organisations start adapting and implementing the same behaviour. Sometimes the unethical behaviour appears in local parts of a network where local elites try to form their own norms of behaviour, contrary to broadly accepted norms of the field. ${ }^{39}$ However acting against some norms may also arise when organisations are uncertain about the exact interpretation of the norm.

Some authors explain the spread of unethical behaviours using the mechanism of social contagion. ${ }^{40}$ This phenomenon may arise under favourable circumstances that include close relations between organisations and social control agents responsible for ensuring the ethics of organisations' actions. ${ }^{41}$ Some promulgated

\footnotetext{
${ }^{38}$ B.E. Ashford, V. Anand, The Normalization of Corruption in Organizations, "Research in Organizational Behavior" 2003, Vol. 25, No. 3, pp. 4-34.

${ }^{39}$ G.F. Davis, H.R. Greve, Corporate Elite Networks and Governance Changes in the 1980s, "American Journal of Sociology" 1997, Vol. 103, No. 1, pp. 1-37.

${ }^{40}$ H.R. Greve, D. Palmer, J. Pozner, op. cit., pp. 79-81.

${ }^{41}$ Examples of the spread of misconduct as a result of unethical actions of professional auditors in: D.A. Moore, P.E. Tetlock, L. Tanlu, M.H. Bazerman, Conflicts of Interest and the Case of Auditor Independence: Moral Seduction and Strategic Issue Cycling, "Academy of Management Review" 2006, Vol. 31, No. 1, pp. 10-29.
} 
rules of conduct might as well provide opportunities for misconduct. Social control agents might also inadvertently set regulations that motivate organisations to behaviours conducive to reducing the risk of being detected, like shredding documents. ${ }^{42}$ Sometimes intrusive checking activities of social control agents might push an organisation to deviance. The legal system might also facilitate creating associations that become an important source of resources necessary for avoiding detection. Their emergence leads also to some group effects like mutual support and group pressure for misconduct. ${ }^{43}$

The spread of unethical behaviour depends also on the level of cohesiveness of the network. Strong ties require a certain level of proximity that might lead to the similarity of attitudes, norms and behaviours. According to the 'homophily' concept, the similarity between actors breeds attraction and the more time they spend together the more similar they become. ${ }^{44}$ That may also entail a similarity in attitudes towards unethical behaviour.

\section{Consequences of unethical behaviour}

The consequences of unethical behaviour are often set in the legal system as criminal and civil sanctions, but there are also some effects that are of an extra-judicial nature. Usually, the shareholders of an organisation, including owners, interactive partners or customers, can assume punitive reactions to such situations. Partners might impose additional costs to ensure the safety of future transaction, to ascertain that the organisation does not repeat its illegitimate actions. ${ }^{45}$ As a rule, market-based sanctions, such as decreasing reputation, should be higher for organisations with a higher status, but, as some research shows, small firms are sometimes punished more harshly. ${ }^{46}$ One of the explanations of this phenomenon is the lack of alternatives for carrying transactions with other, alternative partners. ${ }^{47}$

When an organisation acts in an unethical way its network of ties is prone to changes. ${ }^{48}$ Its partners and customers leave and this process involves, in particular, those with a high status. The reason behind it is that firms with a higher status are

\footnotetext{
${ }^{42}$ On the example of Enron in: B.E. Ashford, V. Anand, op. cit., p. 2.

${ }^{43}$ J.D. Collins, K. Uhlenbruck, P. Rodriguez, Why Firms Engage in Corruption: A Top Management Perspective, "Journal of Business Ethics" 2009, Vol. 87, No. 1, p. 102.

${ }^{44}$ M. McPherson, L. Smith-Lovin, J.M. Cook, Birds of a Feather: Homophily in Social Networks, “Annual Review of Sociology" 2001, Vol. 27, No. 1, pp. 415-444.

${ }^{45}$ S. Jonsson, H.R. Greve, T. Fujiwara-Greve, Undeserved Loss: The Spread of Legitimacy Loss to Innocent Organizations in Response to Reported Corporate Deviance, "Administrative Science Quarterly" 2009, Vol. 54, No. 2, pp. 197-198.

${ }^{46}$ C.R. Alexander, On the Nature of the Reputational Penalty for Corporate Crime: Evidence, "The Journal of Law \& Economics" 1999, Vol. 42, No. 1, p. 520.

${ }^{47}$ An example of this phenomenon in the defense sector can be found in: J.M. Karpoff, D.S. Lee, V.P. Vendrzyk, Defense Procurement Fraud, Penalties, and Contractor Influence, "The Journal of Political Economy" 1999, Vol. 107, pp. 839-840.

${ }^{48}$ F. Zuber, Spread of Unethical Behavior in Organizations: A Dynamic Social Network Perspective, "Journal of Business Ethics" 2015, Vol. 131, No. 1, pp. 151-172.
} 
more at risk of losing their reputation. As research shows, reputation is a doubleedged sword. It can be an important source of competitive advantage, but when firms misbehave or are perceived as connected with the ones that do so, firms of good reputation suffer more market sanctions than those with low reputation. ${ }^{49}$

At the exposure of unethical behaviour, partners linked to the organisation face the decision whether to remain connected with it and risk, as Erving Goffman called it, 'courtesy stigma' or cut the links with the wrongdoer. ${ }^{50}$ Usually, organisations try to avoid association with those labelled negatively, as it may be perceived as a liability and lead to isolation. As they start to defect the network, the effect of imitation again comes into being. More and more organisations start cutting the ties, as a result of response-based imitation (because others are doing it and it is perceived as the right thing to do) or consequence-based defection (on the basis of the assumption that in this situation the survival of the partner is endangered). ${ }^{51}$

Another effect of unethical behaviour is a delegitimization. ${ }^{52}$ Legitimization of organisations' activities is perceived and evaluated by various audiences. Most of them try to simplify their perception by using categorization, that is trying to group organisations with specific characteristics. Unethical behaviour can cause loss of legitimization also for other, quite innocent organisations that are generally perceived as similar. ${ }^{53}$ This mechanism might be reinforced by media releases that are provoking a reaction by the audiences even though they are not really facing any direct consequences of the wrongdoing.

As a consequence, delegitimated organisation's partners may try to avoid effects of being associated with it. That is true especially for large, successful and firms with a good reputation. Information about a partner's misconduct may motivate them to make a decision to sever links with partners with low legitimization. As the information about illegitimacy travels in the network, high-quality partners are not willing to be linked with such an organisation. That is why, for building its network, it may be forced to look for more distant partners. That, in turn, changes the cohesiveness of the network, cutting previous close ties which allow access to reliable information and help to enforce mutually accepted norms.

Avoidance of being linked to the wrongdoer by previous partners is one of the consequences concerning the changes in interorganisational networks after the uncovering of misconduct. ${ }^{54}$ It is often justified by fear of risk that a partner might become a future victim. As stated before such connection may also mean reduced legitimacy for the linked organisations. According to Suchman, 'because legitimi-

\footnotetext{
${ }^{49}$ M. Rhee, P.R. Haunschild, The Liability of Good Reputation: A Study of Product Recalls in the U.S. Automobile Industry, "Organization Science” 2006, Vol. 17, No. 1, p. 113.

${ }^{50}$ E. Goffman, Stigma. Notes on the Management of Spoiled Identity, Simon and Schuster, New York, 1963, pp. 30-31.

${ }^{51}$ M. Jensen, Should We Stay or Should We Go? Status Accountability Anxiety and Client Defections, "Administrative Science Quarterly" 2006, Vol. 51, No. 1, p. 105.

${ }^{52}$ B.N. Sullivan, P. Haunschild, K. Page, op. cit., pp. 55-70.

${ }^{53}$ S. Jonsson, H.R. Greve, T. Fujiwara-Greve, Undeserved Loss: The Spread of Legitimacy Loss to Innocent Organizations in Response to Reported Corporate Deviance, "Administrative Science Quarterly" 2009, Vol. 54, No. 2, p. 221.

${ }^{54}$ Ibidem, pp. 197-198.
} 
zation is frequently mutualistic the risk of negative contagion may drive longstanding allies to dissociate themselves from a troubled counterpart. ${ }^{55}$ Sometimes partners decide to sever the ties just because they do not tolerate unethical behaviour by partners. ${ }^{56}$

\section{Summary}

The effect of being interconnected with other organisations on the occurrence and spread of unethical behaviour became a popular area of scientific interest at the beginning of the $21^{\text {st }}$ century. Previous network analyses of misconduct traditionally concentrated on the level of social ties between individuals within an organisation. Contemporary research concerning this subject is heading toward comprehensive analysis of so-called 'whole' networks, meaning networks of interconnected organisations.

This area of research is relatively new and there are many directions that require further analysis in the future. Some of them, like strain and culture on the macro level, have already been mentioned in the text above. However, the review of the literature on this subject revealed some other areas as well.

Most of the research available today is based upon a static analysis of networks in a given time. Introducing a dynamic approach, including changes of the networks over time, might explain why some of the network analyses provide inconsistent results. Longitudinal studies may also reveal some mechanisms that cannot be seen on the basis of static analysis or over short periods of time.

Another area that, in my opinion, requires further analysis is the influence of such factors, as: types of network, network position, structural holes and cliques, on the occurrence of unethical behaviour. Although there are some studies by various authors, they often either regard the level of a single organisation, or deliver inconsistent or contradictory results.

\section{References}

Adler P.S., S. Kwon, Social Capital: Prospects for a New Concept, "The Academy of Management Review" 2002, Vol. 27, No. 1, pp. 17-40, http://doi.org/10.5465/ AMR. 2002.5922314.

Alexander C.R., On the Nature of the Reputational Penalty for Corporate Crime: Evidence, "The Journal of Law \& Economics" 1999, Vol. 42, No. 1, pp. 489-526, http://dx.doi. org/10.1086/467433.

\footnotetext{
${ }^{55}$ M.C. Suchman, Managing Legitimacy: Strategic and Institutional Approaches, "Academy of Management Review" 1995, Vol. 20, No. 3, p. 597.

${ }^{56}$ Although in certain situations other factors might overcome the lack of tolerance for unethical behaviour. An example in: W. Drover, M.S. Wood, Y. Fassin, Take the money or run? Investors' ethical reputation and entrepreneurs' willingness to partner, “Journal of Business Venturing” 2014, Vol. 29, №. 6, pp. 723-740.
} 
Ashforth B.E, V. Anand, The Normalization of Corruption in Organizations, "Research in Organizational Behavior" 2003, Vol. 25, No. 2, pp. 1-52, http://dx.doi.org/10.1016 /S0191-3085(03)25001-2.

Ashforth B.E., D.A. Gioia, S.L. Robinson, L.K. Treviño, Re-Viewing Organizational Corruption, "Academy of Management Review" 2008, Vol. 33, No. 3, pp. 670-684, http://dx.doi.org/10.2307/20159430.

Ashkanasy N.M., C.A. Windsor, L.K. Treviño, Bad Apples in Bad Barrels Revisited: Cognitive Moral Development, Just World Beliefs, Rewards, and Ethical Decision-Making, "Business Ethics Quarterly" 2006, Vol. 16, No. 4, pp. 449-473, http://dx.doi.org/10. 5840/beq200616447.

Brass D.J., K.D. Butterfield, B.C. Skaggs, Relationships and Unethical Behavior - A Social Network Perspective, "Academy of Management Review" 1998, Vol. 23, No. 1, pp. 14-31, http://doi.org/10.2307/259097.

Briscoe F., S. Safford, The Nixon-In-China Effect: Activism, Imitation, and the Institutionalization of Contentious Practices, "Administrative Science Quarterly" 2008, Vol. 53, pp. 460-491, http://dx.doi.org/10.2189/asqu.53.3.460.

Burt R.S., Structural Holes, Harvard University Press, Harvard 1995.

Collins J.D., K. Uhlenbruck, P. Rodriguez, Why Firms Engage in Corruption: A Top Management Perspective, "Journal of Business Ethics" 2009, Vol. 87, No. 1, p. 89-108, http://dx.doi.org/10.1007/s10551-008-9872-3.

Coyle-Shapiro J.A.M., Shore L.M., The employee-organization relationship: Where do we go from here?, "Human Resource Management Review" 2007, Vol. 17, No. 2, pp. 166-179.

Davis G.F., H.R. Greve, Corporate Elite Networks and Governance Changes in the 1980s, "American Journal of Sociology" 1997, Vol. 103, No. 1, pp. 1-37, http://doi.org/10. $1086 / 231170$.

Drover W., M.S. Wood, Y. Fassin, Take the Money or Run? Investors' Ethical Reputation and Entrepreneurs' Willingness to Partner, "Journal of Business Venturing" 2014, Vol. 29, No. 6, pp. 723-740, http://doi.org/10.1016/j.jbusvent.2013.08.004.

Goffman E., Stigma. Notes on the Management of Spoiled Identity, Simon and Schuster, New York 1963.

Granovetter M., Economic Action and Social Structure: The Problem of Embeddedness, “American Journal of Sociology" 1985, Vol. 91, No. 3, pp. 481-510, http://doi.org /10.1086/228311.

Granovetter M., The Strength of Weak Ties, “American Journal of Sociology" 1973, Vol. 78, No. 6, pp. 1360-1380, http://doi.org/10.1086/225469.

Greve H.R., D. Palmer, J. Pozner, Organizations Gone Wild: The Causes, Processes, and Consequences of Organizational Misconduct, "The Academy of Management Annals" 2010, Vol. 4, No. 1, pp. 53-107, http://doi.org/10.1080/19416521003654186.

Gulati R., M. Sytch, Dependence Asymmetry and Joint Dependence in Interorganizational Relationships: Effects of Embeddedness on a Manufacturer's Performance in Procurement Relationships, "Administrative Science Quarterly” 2007, Vol. 52, No. 1, pp. 32-69, http://doi.org/10.2189/asqu.52.1.32.

Harris J., P. Bromiley, Incentives to Cheat: The Influence of Executive Compensation and Firm Performance on Financial Misrepresentation, "Organization Science" 2007, Vol. 18, No. 3, pp. 350-367, http://doi.org/10.1287/orsc.1060.0241. 
Haunschild P.R., A.S. Miner, Modes of Interorganizational Imitation: The Effects of Outcome Salience and Uncertainty, "Administrative Science Quarterly" 1997, Vol. 42, No. 3, pp. 472-500, http://dx.doi.org/10.2307/2393735

Jensen M., Should We Stay or Should We Go? Status Accountability Anxiety and Client Defections, "Administrative Science Quarterly" 2006, Vol. 51, No. 1, pp. 97-128, http:// doi.org/10.2189/asqu.51.1.97.

Jonsson S., H.R. Greve, T. Fujiwara-Greve, Undeserved Loss: The Spread of Legitimacy Loss to Innocent Organizations in Response to Reported Corporate Deviance, "Administrative Science Quarterly" 2009, Vol. 54, No. 2, pp. 195-228, http://doi.org/10. 2189/ asqu.2009.54.2.195.

Karpoff J.M., D.S. Lee, V.P. Vendrzyk, Defense Procurement Fraud, Penalties, and Contractor Influence, "The Journal of Political Economy" 1999, Vol. 107, pp. 809-842, http://doi.org/10.3386/w19846.

Kulik B.W., Agency Theory, Reasoning And Culture at Enron: In Search of a Solution, "Journal of Business Ethics" 2005, Vol. 59, No. 4, pp. 347-360, http://dx.doi.org/10.1007/s10551-004-7308-2.

McPherson M., L. Smith-Lovin, J.M. Cook, Birds of a Feather: Homophily in Social Networks, "Annual Review of Sociology" 2001, Vol. 27, No. 1, pp. 415-444, http://doi. org/10.1146/annurev.soc.27.1.415.

Melé D., The Practice of Networking: An Ethical Approach, "Journal of Business Ethics" 2009, Vol. 90, No. 4, pp. 487-503, http://doi.org/10.1007/s10551-010-0602-2.

Moore D.A., P.E. Tetlock, L. Tanlu, M.H. Bazerman, Conflicts of Interest and the Case of Auditor Independence: Moral Seduction and Strategic Issue Cycling, "Academy of Management Review" 2006, Vol. 31, No. 1, pp. 10-29, http://dx.doi.org/10.5465 /AMR.2006.19379621.

Palmer D., C. Moore, Social Networks and Organizational Wrongdoing in Context [in:] Organizational Wrongdoing, eds. D. Palmer, R. Greenwood, K. Smoth-Crowe, Cambridge University Press, Cambridge 2016, pp. 153-170.

Pinto, J. C.R. Leana, F.K. Pil, Corrupt or Organizations of Corrupt Individuals? Two Types of Organization-Level Corruption, "Academy of Management Review" 2008, Vol. 33, No. 3, pp. 685-709, http://dx.doi.org/10.5465/AMR.2008.32465726.

Provan K.G., A. Fish, J. Sydow, Interorganizational Networks at the Network Level: A Review of the Empirical Literature on Whole Networks, "Journal of Management" 2007, Vol. 33, No. 3, p. 479-516, http://dx.doi.org/10.1177/01492063073 02554.

Provan K.G., J.G. Sebastian, Networks Within Networks: Service Link Overlap, Organizational Cliques, and Network Effectiveness, "Academy of Management Journal" 1998, Vol. 41, No. 4, pp. 453-463, http://doi.org/10.2307/257084.

Rhee M., P.R. Haunschild, The Liability of Good Reputation: A Study of Product Recalls in the U.S. Automobile Industry, "Organization Science" 2006, Vol. 17, No. 1, pp. 101117, http://doi.org/10.1287/orsc.1050.0175.

Rogers E.M., Diffusion of Innovations, The Free Press, New York 1995.

Rowley T.J., H.R. Greve, H. Rao, J.A. Baum, A.V. Shipilov, Time to Break Up: Social and Instrumental Antecedents of Firm Exits from Exchange Cliques, "The Academy of Management Journal" 2005, Vol. 48, No. 3, p. 499-520, http://dx.doi.org/ 10.5465/ AMJ.2005.17407914. 
Seevers M.T., S.J. Skinner, S.W. Kelley, A Social Network Perspective on Sales Force Ethics, "Journal of Personal Selling \& Sales Force Management" 2008, Vol. 33, No. 1, pp. 231-251, http://dx.doi.org/10.2753/PSS0885-3134270405.

Suchman M.C., Managing Legitimacy: Strategic and Institutional Approaches, "Academy of Management Review" 1995, Vol. 20, No. 3, pp. 571-610, http://doi.org/10.5465 /AMR.1995.9508080331.

Sullivan B.N., P. Haunschild, K. Page, Organizations Non Gratae? The Impact of Unethical Corporate Acts on Interorganisational Networks, "Organization Science" 2007, Vol. 18, No. 1, pp. 55-70, http://doi.org/10.1287/orsc.1060.0229.

Sykes G.M., D. Matza, Techniques of Neutralization: A Theory of Delinquency, "American Sociological Review" 1957, Vol. 22, No. 6, pp. 664-670, http://dx.doi.org/10. 2307/ 2089195.

Tenbrunsel A.E., K. Smith-Crowe, Ethical Decision Making: Where We've Been and Where We're Going, "The Academy of Management Annals" 2008, Vol. 2, No. 1, pp. 545-607, http://dx.doi.org/10.1080/19416520802211677.

Uzzi B., Social Structure and Competition in Interfirm Networks: The Paradox of Embeddedness, "Administrative Science Quarterly" 1997, Vol. 42, No. 1, pp. 35-66, http:// doi.org/10.2307/2393808.

Westphal J., P. Khanna, Keeping Directors in Line: Social Distancing as a Control Mechanism in the Corporate Elite, "Administrative Science Quarterly" 2003, Vol. 48, No. 3, pp. 361-398, http://doi.org/10.2307/3556678.

Wiesenfeld B.M., K.A. Wurthmann, D.C. Hambrick, The Stigmatization and Devaluation of Elites Associated with Corporate Failures: A Process Model, "Academy of Management Review” 2008, Vol. 33, No. 1, pp. 231-251, http://doi.org/10.5465/AMR. 2008.27752771.

Zuber F., Spread of Unethical Behavior in Organizations: A Dynamic Social Network Perspective, "Journal of Business Ethics" 2015, Vol. 131, No. 1, pp. 151-172, http://doi. org/10.1007/s10551-014-2270-0. 